\title{
Raise your glasses - the water's magic! Strategic IT at SA Water: a case study in alignment, outsourcing and governance
}

\author{
Alan Thorogood', Philip Yetton', Anthony Vlasic ${ }^{1}$, Joan Spiller ${ }^{3}$ \\ ${ }^{1}$ Australian Graduate School of Management, UNSW, Sydney, Australia; \\ ${ }^{2}$ CORDS Limited, Sydney, Australia; \\ ${ }^{3}$ Welsearch Limited, Melbourne, Australia
}

Correspondence:

A Thorogood, Australian Graduate School of Management, UNSW, Sydney, Australia.

Tel: 61299319249

Fax: 61296627621

E-mail: alant@agsm.edu.au

\begin{abstract}
The South Australian Water case study illustrates the management challenges in aligning Information Technology with business objectives in a publicly owned corporation. To achieve the alignment, the new $\mathrm{ClO}$ begins by refreshing the IT infrastructure to support the required business applications. When the Government establishes 'Improved water quality' as a major corporate goal, the $\mathrm{ClO}$ seeks to add value to the business by developing a quality reporting system that leverages the existing technology. At the same time, he demonstrates to the corporation the IT function's capability to deliver business value through the management of multiple outsourcing vendors.
\end{abstract}

Journal of Information Technology (2004) 19, 130-139. doi:10.1057/palgrave.jit.2000017

Published online 13 July 2004

Keywords: outsourcing; strategy; project management; governance; government

\section{Introduction}

S outh Australian Water (SA Water) is responsible for the secure supply of quality water to Adelaide and the world famous Barossa Valley vineyards. Much of South Australia is the Great Sandy Desert and the largest river, the Murray, is both shrinking and unpotable. SA Water addresses this challenge through an internationally recognised water-testing laboratory.

\section{Historical context}

Water delivery is an ancient technology, which changed little until the introduction of electric pumps. It has always been more economical to lay one large pipe between two localities than it is to lay two smaller pipes. So, water delivery is a natural monopoly and is therefore often government owned or regulated.

Over the years, SA Water had evolved into a vertically integrated government department. In the past, its scope spanned from managing the catchment areas to retail billing and it had its own castings factory to make pipes. At its peak, it employed 6000 people, many of whom had joined the organisation as apprentices and worked their way up through the ranks.

During the 1990s, the South Australian Government outsourced its IT infrastructure to EDS, privatised some State-owned businesses and corporatised others, including SA Water. After being restructured as a Government-owned corporation, SA Water outsourced the maintenance and operations of Adelaide's water supply to United Water, a joint venture of Thames Water, Vivendi Water and Halliburton KBR. It also sold the castings business. This reflected SA Water's goals, which had changed from 'security of supply' to 'efficient security of supply'. More than 4000 employees left, many of them to join United Water.

\section{Business background}

In the late 1990s, the Government became increasingly concerned with environmental issues and added water quality to the goals. The Government also directed the Corporation to become more customer-focused, more commercial and to develop a vigorous export-focused 
water industry based on the water-testing laboratory while providing a high-quality water supply.

The Government also appointed a new CEO, Anne Howe. She structured the organisation along functional lines with a separate business unit to manage the water-testing laboratory. In February 2003, the largest functional unit was Water Services, under John Ringham, incorporating Operations, Engineering and Projects, Infrastructure and Retail. The unit worked closely with United Water to implement and monitor projects. The Economic Development and Procurement function, headed by Jeremy Randell, was responsible for long term planning and directing the multi-million dollar investments that require South Australian Cabinet approval. (See Appendix A, organisation chart.)

The critical function for this case study was Water Technology, headed by Jack McKean. Through its capital planning capabilities, Water Technology interfaced with Economic Development and Procurement, and via its engineering, it assisted Water Services. The Information Services unit reported directly to McKean. McKean's group also included the laboratory, called the Australian Water Quality Centre, whose goals and culture are more scientific than operational. The laboratory is located at Bolivar, a 40min drive from SA Water's head office in the Adelaide central business district.

\section{Information systems: a new direction}

SA Water had a history of poor IT performance and, specifically, a reputation for uncompleted projects. This record did not encourage the business to invest in IT and some business units bypassed the IT function. For example, Water Services developed and maintained the SCADA ${ }^{1}$ system. Also, SA Water did not invest in the Geographical Information System beyond its initial implementation in the $1980 \mathrm{~s}$. Typically, such systems are favoured in utilities.

In 1999, the CEO brought in an external appointee, David Johnston, as CIO. At that time, the IT infrastructure was unable to operate industry standard systems, for example, it could not even support an effective email service. Johnston introduced the concept of business-focused IT and set out to raise the IT profile throughout the organisation. He closed most of the old incomplete projects and proposed and won approval for a major upgrade in IT infrastructure to support the development of new systems in September 2000. A major network upgrade followed. A new email system became available in 2001, followed by a successful widespread upgrade of PCs. This upgrade was not intended to, and indeed it did not, deliver any substantive business benefits. The upgrade built a platform for future valuecreating IT applications. The critical next step was to demonstrate that IT could deliver benefits to the business as a whole.

Johnston changed the division's name to Information Services (IS) and established a goal to 'deliver the right information, at the right time, to the right destination regardless of the location'. To achieve this goal, the CIO publicly stated that IS would need to understand the business more and become business-focused. Under Johnston's model of IS, the business owns both the information and the systems. His goal was for IS to be a contributor to the strategic future of SA Water. He continuously told the business that it had power and that it must exercise that power at both the strategic and project levels.

Implementing this repositioning of IS led Johnston to a strategic broker model of selective outsourcing (see Appendix B for press coverage of the broker model). Under this model, SA Water's IS set up Service Level Agreements with external strategic partners, such as Aspect Computing, and with its own internal groups. IS retained the responsibility for risk management and the delivery of business benefits. It drew on external partners to provide much of the IT skills and advice. For the internal staff, Johnston recruited people from industry both to upgrade the group's competencies and to change the group's culture. Only the best people from the old IT team survived.

\section{New roles and skills}

Two new senior appointments focusing on implementation reflected this repositioning of IS. Johnston brought in Chris James to develop relationships with strategic business partners and to act as the account manager, representing IS to the business. James was responsible for managing relationships with strategic partners, primarily Aspect Computing, and for managing relationships with other business units such as the laboratory and Water Services.

Ted Budas managed contract relationships with a focus on projects to deliver business benefits. A small consulting team also headed by Budas looked after new systems development and provided IT consulting services to the business. Budas relied on Aspect Computing, an external vendor, to provide technical development staff.

There were also other key new roles. Paul Rafferty looked after Customer Support, which included the internal Help Desk, and support services from EDS and Aspect Computing. John Gradisar's Infrastructure unit was responsible for both the computing infrastructure, such as LANs and servers, and telecommunications. Andrew Yates took responsibility for information delivery. Finally, Johnston developed internal Service Level Agreements covering Infrastructure Services, Customer Support and Information Delivery.

\section{Three new organizational structures}

To support the new direction for Information Systems, Johnson created three new organisational structures. First, a group of senior executives and two independent external consultants met bimonthly as the Information Services Executive Committee. Although the CEO sponsored this meeting, McKean chaired it. The Information Services Executive Committee's purpose was to focus on business issues and ensure that the top team was committed to and satisfied with the projects delivered on their behalf.

Second, a Project Governance Office was established to 'provide assistance to business unit managers to maximise the success of ... IT projects through the application of endorsed methods, tools and techniques' (Guidelines for PGO: Internal memo, 2001). Project managers prepared standard project status documents for the fortnightly Project Governance Office meetings. 


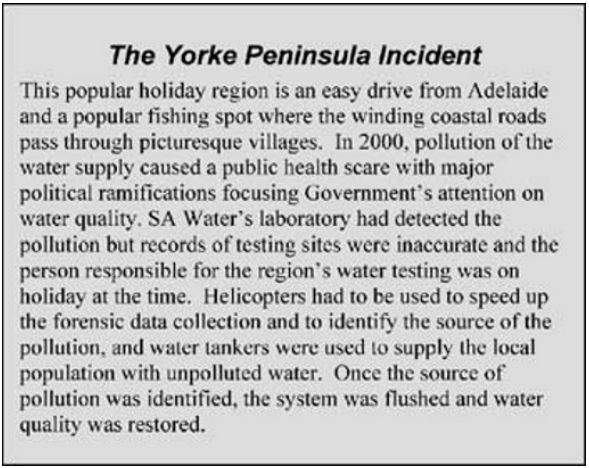

Project 'owners', along with the external strategic alliance partners, attended the Project Governance Office (PGO) meetings, which Johnston chaired. Johnston made it clear that 'the PGO does not have authority over individual IT projects. That accountability rested with the business unit owners.' The PGO advised project managers and identified, investigated and reported on significant variances from plan, particularly time, cost or quality variances. In practice, the PGO dealt with a wide range of issues because it was the corporatewide forum for project managers to discuss issues and share tacit knowledge.

At the PGO, each project manager made a presentation and filed a written report on progress, issues, action to resolve issues and budget variances. During the meeting, people were encouraged to record learnings in the knowledge management system. The PGO's goal was to ensure that all projects used approved methodologies, standardised metrics and reports.

Third, each IT project had a Project Board. The boards consisted of the project sponsor, a senior supplier representative (in practice, often a senior member of IS) and one or more users. The Project Board initiated the project, authorised each stage, gave advice, closed the project and conducted frequent project reviews.

\section{PRINCE2 process: adopting a new methodology}

The methodology adopted was PRINCE2, which is an open standard, first released in 1989 for the UK Government (Office of Government Commerce, 2002). It is now widely used by Australian Government and UK commercial organisations, establishing processes that cross the project-business interface to enable the business to monitor and control a project.

The Project Board and Project Governance Office were both mandated structures of PRINCE2. Internal and external project managers were required to have received training in PRINCE2. A PRINCE2 consulting company based in Adelaide provided two training courses, an entrylevel certification course and an advanced professional course. One SA Water employee had completed the professional training and two others had received certification. This consulting company also kept SA Water's PRINCE2 documentation up to date to satisfy the evolving needs of the business.

As part of this process, an intranet-based knowledge management system was available to assist project managers. The project manager reviewed this knowledge base before starting a project and was responsible for updating it before closing a project. The Project Governance Office oversighted that process.

\section{Application portfolio}

There were several key applications at SA Water. The mission-critical IT applications were billing, SCADA and laboratory, with the geographical information system (GIS) scheduled to become mission-critical in the long term, when it become the user interface to most systems. The GIS and billing system were managed by the IS department. The SCADA system remotely controlled and monitored the pumps, valves and sensors throughout the distribution network and catchment area. The system operated in a stable environment in comparison with the billing and laboratory systems, where complications existed around vendor issues with billing, and reliability issues with the laboratory. Water Services managed and supported the SCADA.

The Laboratory Information Management System (LIMS) was a stand-alone system on its own hardware. This system automated the tracking of samples within the laboratory, allocation of tests to samples, validation of results, interpretation and report generation. SA Water contracted with Aspect Computing to supply IT contractors to support the system. The laboratory supported and managed this system, with assistance from IS.

\section{The Waterscope project: a showcase of IS}

To integrate the new structure, processes and roles with the business, and to 'sell' the changes to business, Johnston wanted a showcase project that would be visibly successful and deliver business benefits. It had to deliver these benefits by leveraging the new technical infrastructure and demonstrating the broker model of outsourcing. The CEO agreed to the showcase concept and a series of workshops produced a short list of three suitable projects. The Waterscope project was selected in May 2001.

Waterscope's goal was to provide access to timely water quality information needed to manage public health risks, such as the Yorke Peninsula Incident (see sidebar). It would reduce the cycle time between gathering water samples and raising alerts to possible problems, by reducing the impact of the delay before the verified and interpreted test results were available. It would further automate the collection of samples in the field by using barcode-reading PDAs ${ }^{2}$ and automatically publishing unverified results from LIMS as soon as the results were available.

The Gane and Sarson Data Flow Diagram (Figure 1) shows the intended system design, not all of which was implemented. Data would flow from the collection and testing of field samples (top left hand corner) through to the publication of results on the intranet (bottom right hand corner). Waterscope would retrieve information from LIMS and store it in PDAs for the collectors to take to the field. While there would be some field tests, most of the testing would be done in the laboratory. Waterscope would download the test limits for each sample's field tests. If the field test were 'out of bounds', the collector could raise the alarm immediately. The geographical coordinates of the 


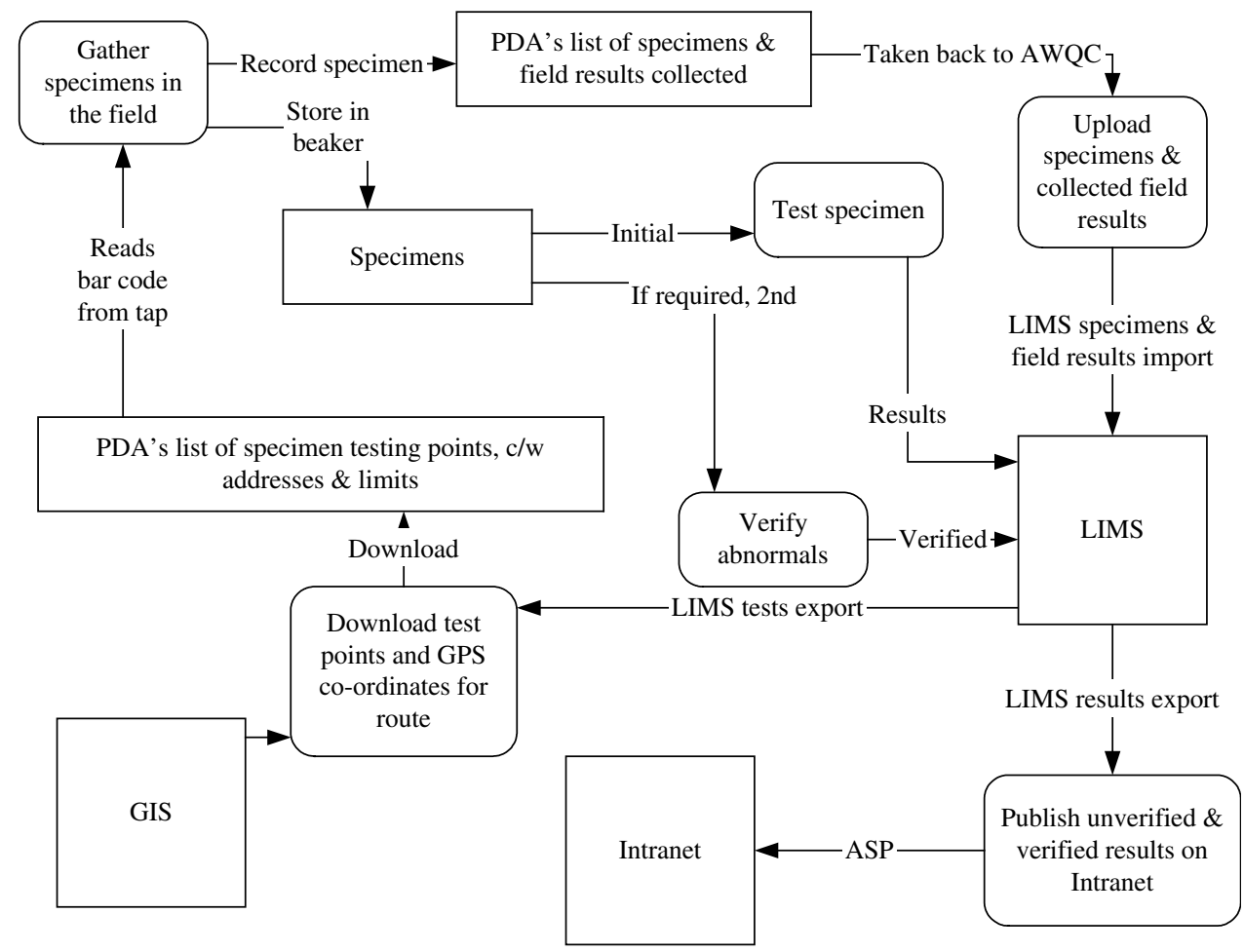

Figure 1 Gane \& Sarson Data Flow Diagram of Waterscope.

Table 1 The Waterscope Stakeholders

Laboratory

Information Services system quickly and minimise risks to public health.

Executive Management

Aspect Computing

DMR encourage support for further IT projects. Government. preferred software supplier.
Waterscope would affect the laboratory staff capturing data in the field. In addition, its goal was to publish laboratory results to the whole organisation. This would increase the transparency of the laboratory's operations while automating its data collection.

IS wanted this project to be both highly visible and highly successful to prove the abilities of the new IS team, infrastructure and outsourcing model. It was to be a 'proof of concept' to

The CEO's objectives with Waterscope were to improve the performance of the company with regard to water quality and cost effectiveness and build credibility with the

Aspect Computing wanted to leverage their knowledge of SA Water systems to become a

DMR's aim was to use the project to bind the vendor-client relationship and become the incumbent Business Intelligence supplier. collection points would secure the system. Before the GPS system was introduced, SA Water relied on local employees who knew how to find the collection points.

The collectors would record the results of the field tests and the collection information, such as water temperature, in the PDA, then upload the data into LIMS when delivering the samples to the laboratory. As soon as the results were available, an Active Server Page would publish them on the intranet, clearly marked as unverified, pending confirmation of any out of bounds results. Once a scientist had verified the results, the intranet would reflect the new status.

In July 2001, the Board approved a small exploratory budget, equivalent to less than $10 \%$ of the total estimate. With this planning budget, the IS team prepared a business case. Building the case required considerable business analysis skill and time, which the small IS team could not provide. Using a broker model of outsourcing, SA Water appointed DMR, Fujitsu's consulting business, on a time and materials basis, to fulfil the role of identifying the benefits and associated costs. By September 2001, the estimated cost had risen by $10 \%$ and the project had to be de-scoped, with assistance from Water Services. ${ }^{3}$ It was then accepted that this was a business project with a technology component, rather than an IS project, and that it would require a large proportion of business analysis work, referred to as Business Intelligence (BI).

Version 1.0 of the business case was developed in late September 2001. SA Water selected DMR as the business 
partner to undertake the Business Intelligence (BI) work, and Aspect Computing as the business partner for the Systems Development (SD) team. In addition to the service providers, the main stakeholders represented on the project were the Water Laboratory, Information Services, Water Services and executive management (see Table 1 for more details).

Johnston appointed DMR consultants to the Project Director role and as the Project Manager for the Business Intelligence team. An Aspect Computing Project Manager headed up the Systems Development team. SA Water Services and laboratory staff, along with Marcel Althoff from IS, were appointed to the BI team.

There were some early conflicts between and misunderstandings about the structure by DMR and Aspect. For example, SA Water had to intervene in the Aspect Computing/DMR relationship to clarify the project manager's reporting lines. Effectively, there were two project teams: Aspect Computing's System Development team of developers and the Business Intelligence team composed of DMR consultants and SA Water managers. The two teams were located on separate floors in the same CBD building. The part-time DMR project director was Melbourne-based and on-site 2 days a week in Adelaide. Most of the users were located at the laboratory in Bolivar, outside Adelaide.

By January 2002, the Information Systems Executive Committee and the SA Water Board had approved the project budget and the project moved into the next phase of the PRINCE2 methodology. In that phase, the SD team received business requirements from the $\mathrm{BI}$ team and then constructed functional specifications. Gaining approval for these functional specifications caused friction because the SA Water people had limited time to approve the specifications, some of which ran to many pages, and the SD team needed approval before it could start to write code.

The DMR project manager, initially dedicated to the BI team, was pulled out early in the project's life to attend to other business in Melbourne. The BI team subsequently took unofficial guidance from Althoff with some contact with the DMR Project Director. Initially, SA Water Services and the laboratory under-resourced the BI team but corrected this in February 2002. Naturally, there were differences between the Aspect team of system developers and the BI team, but the differing interests and cultures within the BI team also reflected the different roles and interests within SA Water.

The Systems Development team reported directly to an Aspect Computing project manager for its day-to-day work. The Aspect Computing appointment was for delivery according to a fixed, but not detailed, specification. To assist in scoping the features and determining the Aspect Computing workload, the BI team categorised the features into mandatory, desirable and nice-to-have. Aspect Computing then estimated their workload based on the mandatory components.

\section{Waterscope project governance}

Figure 2 shows the Waterscope Project Governance organisation chart.

The Project Board met monthly with Todd Heather chairing the meeting. The Project Governance Office met every week up to August 2002 and then fortnightly. These meetings managed issues such as the lack of development skills and availability of SA Water business people for the BI team. Most notably, senior managers on the Project Board were available to resolve conflicts over which desirable, as opposed to mandatory, deliverables were in scope.

\section{Project challenges}

Because projects are unique, it is impossible to predict the outcomes with accuracy and this inevitably creates challenges. In this case, these included:

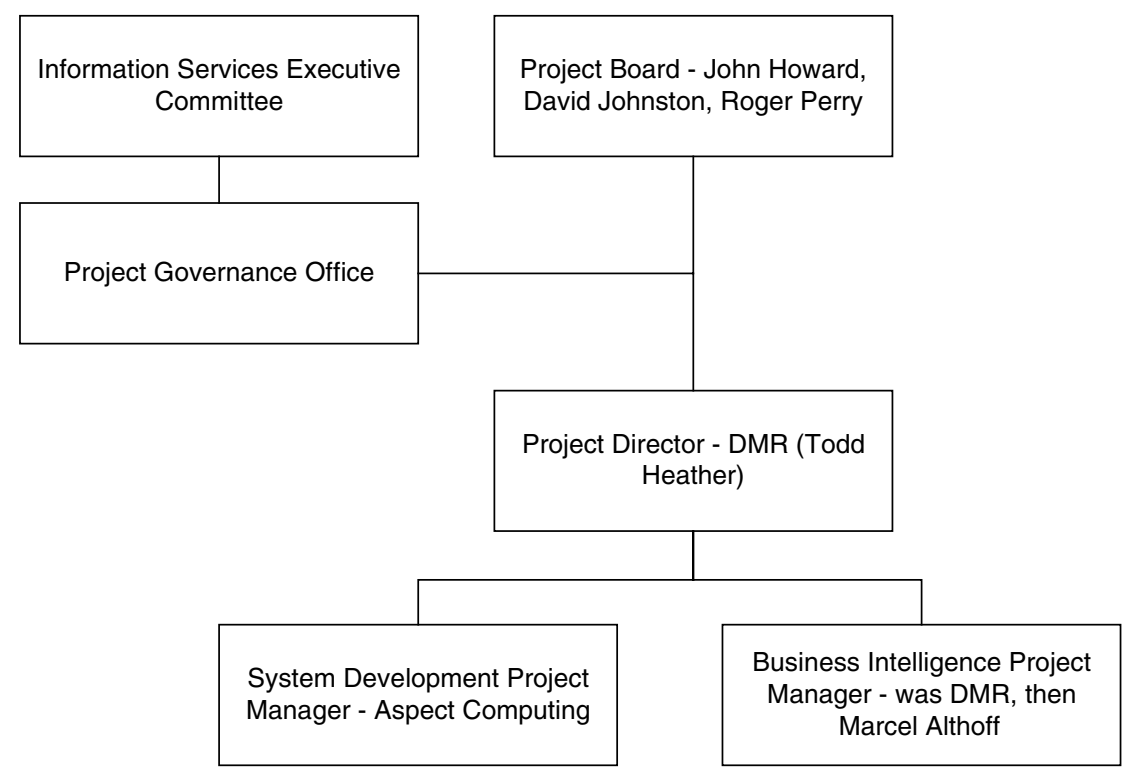

Figure 2 Waterscope Project Governance. 
- A delayed link from the GIS, documented in the January 2002 PGO minutes, caused by unrelated work in a GIS project.

- Problems interfacing with LIMS in February 2002. Neither SA Water IS nor the laboratory understood some of the unusual data structures in LIMS and the quality of the data made it difficult to import into the Waterscope relational database. The initial projectplanning phase did not identify this problem and the simultaneous project to upgrade LIMS made it more complex.

- Delays in PDA testing. Dr Jeremy Lucas, from the laboratory, reported that he was unable to perform testing using a PDA for 2 weeks in March 2002 because key people were on holiday. When the PDA became available in April, testing revealed that it could not read the barcodes, because of the placement of the labels on the pipes. The 350 field labels, which had earlier taken 2 weeks to attach, were then replaced correctly.

- Delays in approval processes in April 2002, because of the lack of available business resources.

- Use of unapproved technology, because there was no software architect to vet the technology. SA Water rejected some technology after partial development, which resulted in re-work.

In some cases, luck was in the project's favour. For example, one of the Aspect Computing people tried scraping off a label and found that the bar codes rubbed off easily. Small changes in printing and ink corrected a fault that only natural ageing would have shown up.

\section{Business outcomes}

By March 2003, the system had been implemented and was operating. The business people interviewed were satisfied with the functions delivered. Many people were aware of the project and recognised it as a success. The project board did not regard the project as complete; they would close the project only when another project delivered a corporatewide data replication capability necessary for full functionality.

Some of the participants felt that, in their experience, the project had cost too much, citing protracted decisionmaking timelines, with the project director unavailable much of the time; time-consuming reporting requirements for the Project Governance Office; technical inexperience and process incompatibility causing poor productivity in some areas; and higher than expected costs of managing the relationships. However, in the historical SA Water context, project performance had been good, with the project delivering most functionality to agreed budgets. As noted earlier, prior to Johnston's arrival, IT projects had a poor record of accomplishment.

The PRINCE2 methodology received a mixed reception. Some described it as too 'heavyweight' for the project. (There were too many mandatory documents and management decisions for the size of the project.) Others saw the benefits as greater than the costs. The main issue of contention was the need to prepare detailed briefing reports for the PGO meetings.

\section{Other projects}

The Works Management System was a major IT application project managed by Water Services. This system was designed to interface with United Water to provide bidirectional inter-organisational links for Works Plans. The project manager attended Project Governance Office meetings and provided updates to the Information Systems Executive Committee but the project did not use the PRINCE2 methodology.

\section{Future plans}

SA Water had many future opportunities to use IT to benefit the organisation following years of low investment. In March 2003, plans included completing the substantial Works Management System discussed above, major upgrades to the GIS over a 5-year period, and installing a Standard Operating Environment for PCs based on Windows XP. SA Water was also considering a billing system replacement. However, replacing it would be a substantial investment. (For example, in New South Wales, Sydney Water had spent $\$ 70.2$ million on a new system, which the New South Wales Treasurer acknowledged was 'likely to be a dud'4.)

Waterscope has also helped to identify additional business benefits that will be low cost to implement with a simple expansion of the system. A Version 2 project may be justified.

\section{Summary}

SA Water has been reorganised into a Government-owned corporation with clearly set goals, including a focus on water quality. The information systems function fell behind industry standards, but the CIO redirected it, refreshed the infrastructure and introduced the broker model of outsourcing. He introduced new roles and skills to match the strategy. The Information Services Executive Committee, Project Governance Office and Project Boards all helped to exercise control over information systems projects. The PRINCE2 methodology integrated these new roles and structures. After these changes the Waterscope project was chosen to showcase the new capabilities.

Waterscope aimed to improve detection and rectification of water quality problems. It consisted of two projects teams, the Aspect Computing Systems Development team and the DMR and SA Water Business Intelligence team, which reported to a DMR project director who then reported to the Project Board. The project overcame some difficulties and relied on the new methods and structures to resolve them. Waterscope was recognised as a success with some qualifications.

\section{Questions to guide case analysis}

1. After Johnston's changes, does the IS function fit the organisation and its environment? In considering the answer to this question, you should draw on models of IT structure and fit. In particular, ask how the new initiatives help IS to get closer to the business.

2. Is it the people, the structure, the methodology, the technology, the top team relationship, vendor support or the project management, that is the key to Waterscope's success? Which of these elements did Johnston emphasise to bring about improvement, and what risks to highperformance project practice remain? 
3. What important issues does this case raise about IS project governance?

4. David Johnston was headhunted and took up a new role in April 2003. What attributes should SA Water look for in a new CIO and what changes should the new CIO make?

\section{Case study participants}

1. MBA students

2. Executives concerned about IS business deliverables.

\section{Notes}

1 SCADA systems are used to monitor and control plant status and provide logging facilities (www.foldoc.org).

2 PDA (Personal Digital Assistant): a rugged mobile hand-held computer that operates on batteries for considerable periods.

3 Much of the cost increase came about because the project costing rules changed. Previously, the accounting system did not allocate internal project costs to the project budget. To stay within the budget approved by the Board, the sponsor had to descope the project. For example, the SCADA interface that would have shown the status of valves was included in the benefits realization plan and but was specifically excluded subsequently.

4 For more details, see The Australian Financial Review 28 October 2002, 'Audit of PwC water-billing job'.

\section{References}

Office of Government Commerce (2002). Introduction to PRINCE2 management overview, http://www.ogc.gov.uk/prince/(accessed 3rd February 2003).

\section{About the authors}

Alan Thorogood is researching theoretical frameworks to assist management thinking with regard to IT flexibility, outsourcing and project management. In the research, he draws on nearly two decades of wide-ranging global industry experience. $\mathrm{He}$ is a $\mathrm{PhD}$ candidate in Professor
Phillip Yetton's Fujitsu Centre for Managing Information Technology and teaches on the AGSM's Executive MBA and full-time programme. The AGSM awarded his MBA in 2003 with the Australian Business Limited Prize for top academic performance and the Boston Consulting Group Prize for performance in strategy.

Philip W. Yetton is the Commonwealth Bank Professor of Management at the AGSM. He is a graduate of Cambridge, Liverpool and Carnegie-Mellon Universities. His major research interests are in ISD project management, IT strategic alignment, SMEs, strategic leadership, and ITbased strategic change. He has extensive consulting experience in both public and private sectors and is coauthor of 'Steps to the Future' and has written more than fifty articles published in international journals.

Anthony Vlasic is a Postdoctoral Fellow at the Australian Graduate School of Management. His major research interests focus on how organisations and industries can improve business value generated from project-based investments, with a particular focus on information system projects. Prior to joining the AGSM, Anthony worked as a project manager in Australia and Europe.

Joan Spiller is Managing Partner of Welsearch Pty Ltd and combines Board Directorships with consultancy work, particularly in strategy and operations. Consultancy fields include IT services, Bio-tech, Building \& Construction, Communications, Health Care, Arts, Education and Defence.

She chairs the Board of Flower \& Samios Architects, and is a Director of several Arts organisations. Past Board Directorships include the Australian Broadcasting Corporation, Victorian Rehabilitation Centre, Monash IVF, Monash Ultrasound for Women, Monash Reproductive Pathology \& Genetics, and the Melbourne Symphony Orchestra. Her extensive experience in public sector policy development and operations includes senior executive positions in Health and Communications. 


\section{Appendix A}

South Australian Water - Abbreviated Organisation Chart at February 2003

South Australian Water - Abbreviated Organisation Chart at February 2003

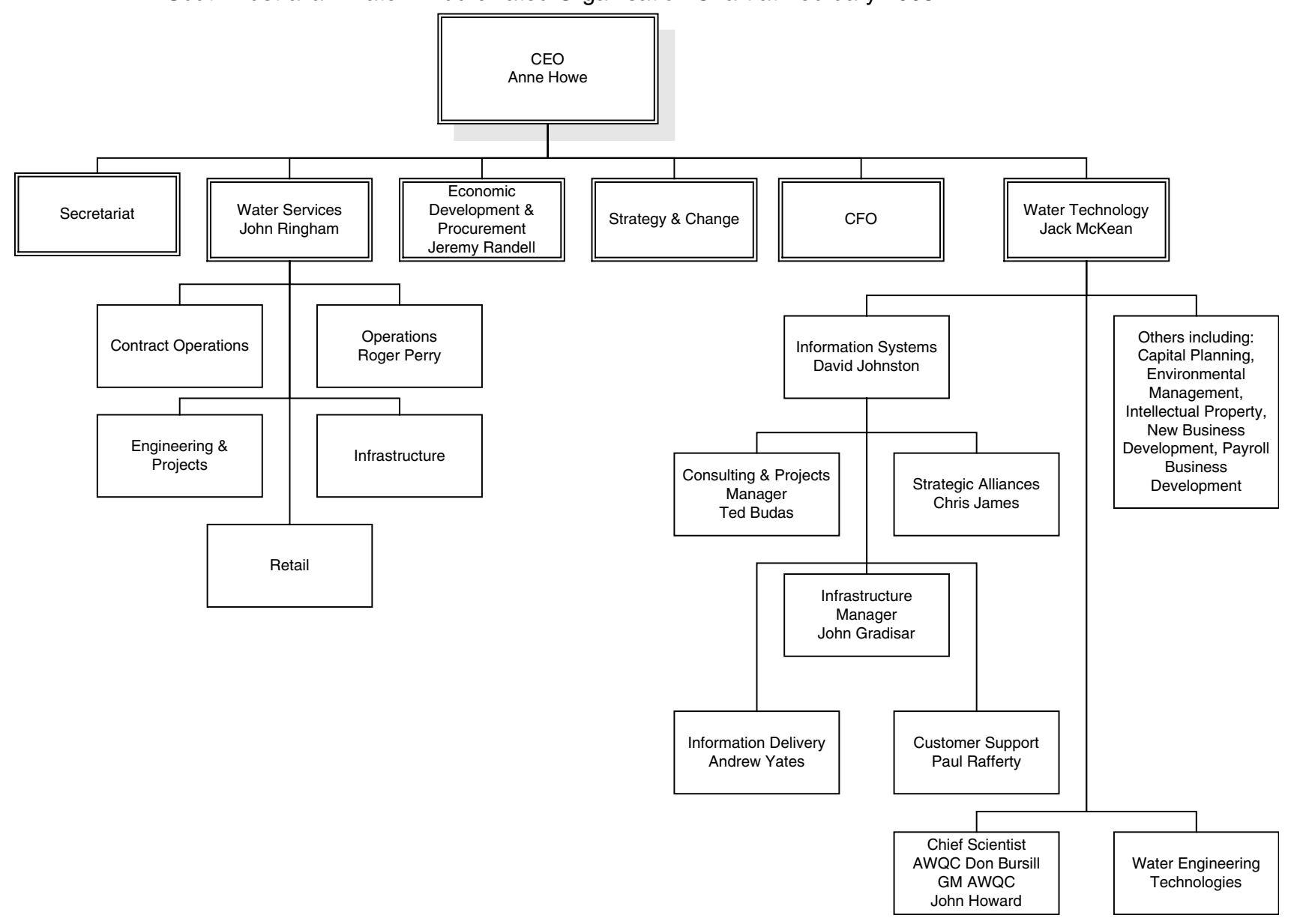

\section{Appendix B}

CIO of tomorrow a service broker (The Australian, 26 June 2001)

\section{IT chiefs should get used to outsourcing, Craig Baty says}

THE Senate's Finance and Public Administration committee is reviewing the Government's IT outsourcing initiative. Whether or not the final findings will praise or damn the outsourcing initiative, Gartner believes that outsourcing, and the use of external service providers in general, will continue to be a viable means of providing services to organisations in both public and private sectors.

Both global and local research leads Gartner to conclude that, by 2002, 80 per cent of enterprises will employ selective IT outsourcing to help control costs, overcome skills shortages and increase the flexibility of labor markets (0.7 probability).
Gartner's Dataquest division predicts that the Australian IT services market (which includes outsourcing as the major component) will grow at a compound annual rate (CAGR) of 20 per cent from its current estimated 2001 size of $\$$ US14.3 billion ( $\$ 27.5$ billion) to $\$$ US24.6 billion by 2004 , making Australia one of the world's fastest growing and advanced markets for outsourcing services.

So what's driving this growth, and what does it mean for the one in the hot seat - the CIO, who is responsible for delivering services?

Driven by an increasingly competitive marketplace and enabled by decreasing unit costs of basic technologies (processors, storage, bandwidth), IT has expanded from a back-room resource providing competitive advantage (cost, time, quality), into a front-office resource (marketing, sales, environmental scan) that is a competitive necessity and essential for the survival of the enterprise. 
Change, once viewed as a short period of transition between two longer periods of relative stability, is now a continuous process.

At the same time, the concept of a monolithic enterprise owning all products, services and channels required to address a customer's needs is rapidly being replaced by strategic partnerships, virtual enterprises and integrated value chains.

This new environment is generating new critical success factors for IT investment. The need to operate in a dynamic business and technical environment is driving the need for technology infrastructures and application architectures that are flexible, maintainable and easy to integrate (while still providing functionality, cost-effectiveness and a timely and secure environment).

The traditional, centralised Information Systems (IS) organisation of past years is rapidly giving way to a more distributed structure.

We call this a role-based organisation because it represents an association of multiple organisational styles and sources that fulfil different roles for the enterprise.

While the IS organisation would not disappear, we do believe its form will change dramatically, encompassing a mix of service organisations, consultants, centres of excellence, resource pools and business liaisons, rather than a single integrated IT function within the business.

Many of the traditional functions of the IS organisation are moving to the business units or to external service providers (ESPs). These various structures can be thought of as organisational tools that need to be brokered and coordinated.

This is the chief role of the new IS organisation, and by extension the CIO. In fact, for most enterprises, the new IS organisation will be dramatically smaller and more business-focused. Total IT employment will continue to grow, but the number of those on the internal payroll may very well shrink, with many staff moving to external service providers.

Gartner expects that by 2002, the primary focus of IT management will shift from operational efficiency and effectiveness to information exploitation and inter-enterprise operability ( 0.7 probability) and by 2004 , fewer than 30 per cent of medium to large enterprises will maintain a full-service (internal) IS organisation ( 0.8 probability).
Gartner expects the IS organisation to be a more modular, flexible organisation that will align more closely with the speed of change in the enterprise than traditional structures could. While some enterprises will completely outsource all IT functions, and it is likely more than 85 per cent of enterprises will need some form of an internal IS organisation, albeit significantly changed in size and scope.

The lack of relevant IT skills in the market is driving many of the above changes to the traditional IS role and structure. Enterprises that were once accustomed to having enough IT professionals for every open position are now facing a systemic scarcity of relevant IT skills.

In fact, it is likely the current workforce shortage in many areas (but not all) is a long-term issue that will continue through 2003, as organisations are fundamentally restructured to meet evolving business requirements.

In fact, IS organisations will increasingly focus on strengthening enterprise-specific business and IT management skills while selectively outsourcing technology-intensive external resources to handle operational or short-term activities.

Employment models and workforce values will change dramatically.

Permanent full-time employment will no longer be the standard; IT professionals will insist on continuous learning, opportunities to expand their experience portfolio and the right to request and receive intriguing new types of work.

To accommodate the needs of a changing workforce and organisational dynamics, management styles will have to change.

Treating employees well, paying them fairly, providing meaningful work, tying work to enterprise objectives, broadening work roles and trusting employees, all are crucial to making enterprises attractive.

But responding to the challenges of increased service provider reliance will require a dramatic rethinking of how the IS organisation is run.

The role of the CIO in this new world, thus moves from one of operational efficiencies and effectiveness, to that of being a broker of services.

Craig Baty is group vice-president of Gartner Research Asia-Pacific and Japan, based in Tokyo. E-mail: craig.baty@gartner.com 


\section{Appendix C}

South Australian Water - Time Line

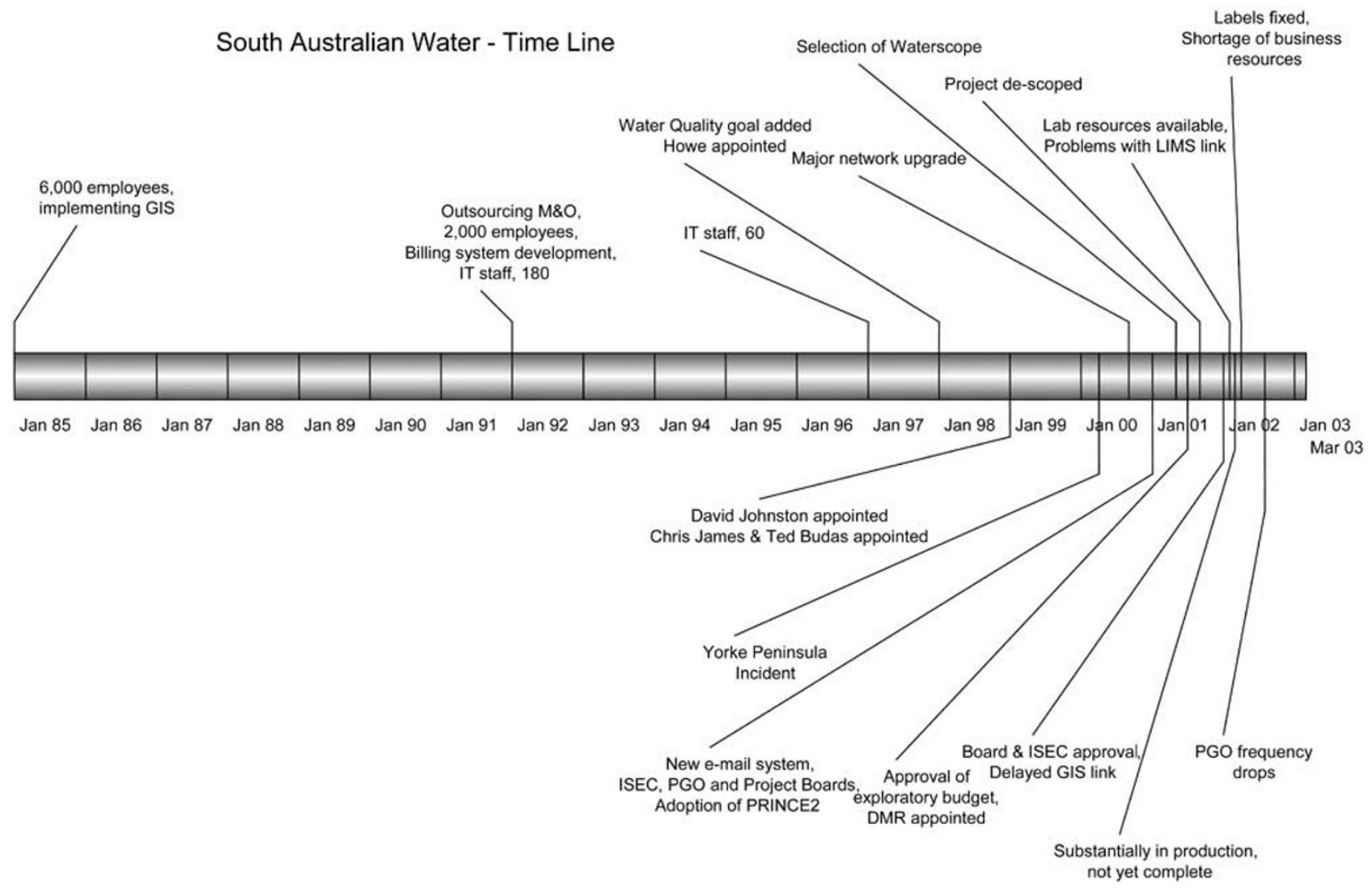

